\title{
A multicopy Y-chromosomal SGNH hydrolase gene expressed in the testis of the platyfish has been captured and mobilized by a Helitron transposon
}

Marta Tomaszkiewicz ${ }^{1,3}$, Domitille Chalopin ${ }^{1}$, Manfred Schartl2 ${ }^{2}$ Delphine Galiana ${ }^{1}$ and Jean-Nicolas Volff ${ }^{*}$

\begin{abstract}
Background: Teleost fish present a high diversity of sex determination systems, with possible frequent evolutionary turnover of sex chromosomes and sex-determining genes. In order to identify genes involved in male sex determination and differentiation in the platyfish Xiphophorus maculatus, bacterial artificial chromosome contigs from the sex-determining region differentiating the $Y$ from the $X$ chromosome have been assembled and analyzed.

Results: A novel three-copy gene called teximY (for testis-expressed in Xiphophorus maculatus on the $Y$ ) was identified on the $Y$ but not on the $X$ chromosome. A highly related sequence called texim 1, probably at the origin of the $Y$-linked genes, as well as three more divergent texim genes were detected in (pseudo)autosomal regions of the platyfish genome. Texim genes, for which no functional data are available so far in any organism, encode predicted esterases/lipases with a SGNH hydrolase domain. Texim proteins are related to proteins from very different origins, including proteins encoded by animal CR1 retrotransposons, animal platelet-activating factor acetylhydrolases (PAFah) and bacterial hydrolases. Texim gene distribution is patchy in animals. Texim sequences were detected in several fish species including killifish, medaka, pufferfish, sea bass, cod and gar, but not in zebrafish. Texim-like genes are also present in Oikopleura (urochordate), Amphioxus (cephalochordate) and sea urchin (echinoderm) but absent from mammals and other tetrapods. Interestingly, texim genes are associated with a Helitron transposon in different fish species but not in urochordates, cephalochordates and echinoderms, suggesting capture and mobilization of an ancestral texim gene in the bony fish lineage. RT-qPCR analyses showed that Y-linked teximY genes are preferentially expressed in testis, with expression at late stages of spermatogenesis (late spermatids and spermatozeugmata).
\end{abstract}

Conclusions: These observations suggest either that TeximY proteins play a role in Helitron transposition in the male germ line in fish, or that texim genes are spermatogenesis genes mobilized and spread by transposable elements in fish genomes.

Keywords: Platyfish, Xiphophorus maculatus, Sex determination, Sex chromosomes, Y chromosome, Testis, SGNH hydrolase, Helitron, Transposition

\footnotetext{
* Correspondence: Jean-Nicolas.Volff@ens-lyon.fr

'Institut de Génomique Fonctionnelle de Lyon, Ecole Normale Supérieure de Lyon, Centre National de la Recherche Scientifique UMR 5242, Université de Lyon I, 46 allée d'Italie, Lyon 69364, Lyon Cedex 07, France

Full list of author information is available at the end of the article
} 


\section{Background}

In contrast to the situation observed in mammals and birds, where sex determination systems and master sexdetermining genes have been conserved over long periods of evolution, sex determination is hypervariable in teleost fish [1-4]. Related fish species and even populations can have different genetic sex-determining systems, with various impact of environmental factors. Fish sex chromosomes are generally poorly differentiated. They are therefore considered to be evolutionary young and might have emerged independently in different fish lineages. Hence, parallel studies on different fish models are necessary to better understand the evolutionary dynamics of sex determination in fish.

Such studies have demonstrated that different, even closely related fish species can have different master sexdetermining genes. The first master sex-determining gene in fish has been identified in the medaka Oryzias latipes. This gene, dmrt1bY, is a Y-chromosomal duplicate of the autosomal gene $d m r t 1$, which encodes a transcription factor with DM domain involved in male development in vertebrates [5,6]. Interestingly, $d m r t 1 b Y$ is not present in related species from the same genus, which therefore must possess other master sex-determining genes. This is the case in Oryzias luzonensis, where the putative master sex-determining gene is gsdf (gonadal soma-derived growth factor), another gene from the sex-determining cascade [7].

More distant species have also different master sexdetermining genes. In the Patagonian pejerrey Odontesthes hatcheri, a Y-linked duplicate of the amh gene, which encodes the anti-Müllerian hormone belonging to the TGF$\beta$ superfamily, might drive sex determination [8]. In the rainbow trout Oncorhynchus mykiss, the master sexdetermining $s d Y$ is a Y-specific duplicate of the interferon regulatory factor 9 gene [9]. Added to the results obtained in O. latipes, these observations underline the importance of gene duplications in the formation of new master sexdetermining genes in fish. However, the situation is different in pufferfishes from the Takifugu genus. In Takifugu, phenotypic sex might be controlled by two alleles of the anti-Müllerian hormone receptor type II gene amhr2, which is located on both the $\mathrm{X}$ and $\mathrm{Y}$ chromosomes. A single nucleotide polymorphism differentiating both alleles affects one amino-acid in the kinase domain of Amhr2. Females are always homozygous for one allele, while males are heterozygous [10]. Hence, hypervariability of sex determination might be associated with frequent evolutionary switch of master sex-determining genes at the top of more conserved downstream components of the sex determination and differentiation cascade, following the principle of "masters change, slaves remain" [11]. Further studies on different fish models are necessary to test the extent of this hypothesis.
Another classical fish model to study sex determination is the platyfish Xiphophorus maculatus. This species possesses three different types of sex chromosomes: $\mathrm{X}, \mathrm{Y}$ and $\mathrm{W}$. Males can be XY or YY, while XX, WX and WY genotypes lead to female development [12]. Using a strain with $\mathrm{XY}$ male heterogametic sex determination, the positional cloning of sex-linked genes has been initiated. A bacterial artificial chromosome (BAC) genomic library of $\mathrm{XY}$ males has been constructed, and BAC contigs covering the region differentiating the $\mathrm{X}$ from the $\mathrm{Y}$ chromosome have been assembled and sequenced $[13,14]$. Very recently, the genome of an XX female has been sequenced [15]. The sex-determining region was found to be prone to DNA rearrangements including deletions, transpositions and duplications $[12,16]$. We report here the identification of a novel gene called texim $Y$, which is found in there copies on the platyfish Y chromosome but absent from the $\mathrm{X}$ chromosome. This gene is preferentially expressed in testis, and has been captured and mobilized by a Helitron transposon in fish.

\section{Results}

Three texim $Y$ genes are clustered in the sex-determining region of the platyfish $Y$ chromosome but are absent from the $X$ chromosome

Four overlapping Y-linked BAC clones (B14, B29, B17 and N20; Figure 1) from the Rio Jamapa platyfish BAC genome library [13] were sequenced to completion and assembled, resulting in a total sequence of 585,694 bp in length. BAC clone B29 contained a pseudogene called Y-cript. PCR analyses demonstrated the presence of $Y$-cript in all males tested ( $>200$ individuals) but its absence from all females (> 200 individuals) (data not shown). Hence, the four assembled BAC clones are closely linked to the master sexdetermining gene on the $\mathrm{Y}$ chromosome, or may even contain it.

Further sequence analysis revealed the presence of three copies of a new gene candidate that was called teximY (for testis-expressed in Xiphophorus maculatus on the $\mathrm{Y}$ ) in a region of approximately $300 \mathrm{~kb}$ (Figures 1 and 2). These three genes were detected neither in BAC clones specific of the $\mathrm{X}$ chromosome nor in the genome sequence of an XX female ([15]; http://www.ensembl. org/Xiphophorus_maculatus/Info/Index). The presence of texim $Y a$, texim $Y b$ and texim $Y c$ was tested by PCR in 34 platyfish individuals from the Rio Jamapa population (17 males and 17 females). All males tested were positive for the three genes, while all females were negative. This confirmed the presence of texim $Y a$, texim $Y b$ and texim $Y c$ on the $Y$ chromosome of the platyfish in the Rio Jamapa population. Texim $Y$ genes are located at distances between 80 and $280 \mathrm{~kb}$ near Y-cript and linked to two copies of a type 4 melanocortin receptor gene mc4r [14]. 


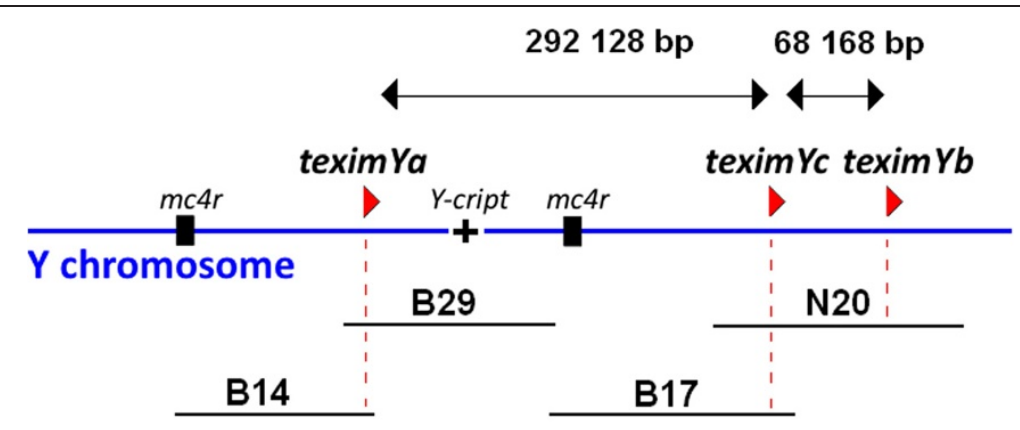

$100 \mathrm{~kb}$

Figure 1 Structure of the teximY gene cluster in the sex-determining region of the $Y$ chromosome of Xiphophorus maculatus. Red arrowheads show the position and predicted transcription orientation of teximY copies. The four sequenced BAC clones (B14, B29, B17 and N20) are shown as black lines. The distance between teximY copies is given. Locations of the Y-specific Y-cript pseudogene and of two copies of the type 4 melanocortin receptor gene $m c 4 r$ [14] are indicated.

All three texim $Y$ copies were in the same transcriptional orientation (Figure 1). They showed 95-98\% nucleotide identity at the cDNA level and $89-97 \%$ amino acid similarity, suggesting recent duplication events. Software-based gene structure prediction as well as sequence comparison with platyfish expressed sequence tags and sequencing of RT-PCR and RACE-PCR products indicated that the texim $Y a$ and texim $Y b$ genes are both composed of 15 exons, while teximYc is a truncated version lacking the last two 3' exons (Figure 2). Sequence comparison of texim $Y a$ and texim $Y b$ flanking regions revealed extensive sequence identity for more than $5 \mathrm{~kb}$ upstream and more than $7 \mathrm{~kb}$ downstream of the genes, suggesting a duplication of at least $25 \mathrm{~kb}$. This analysis could not be performed for teximYc neighboring regions due to the missing adjacent genomic sequences.

BLAST analysis of the platyfish female genome sequence [15] revealed the presence of several texim $Y$-related sequences. These sequences were not present on sexchromosomal BAC contigs covering the region differentiating the $\mathrm{X}$ from the $\mathrm{Y}$ chromosome [13,14]. They are therefore located either on autosomes, or alternatively in homologous regions of the $\mathrm{X}$ and the $\mathrm{Y}$ chromosomes (pseudoautosomal regions). One copy called texim1 presented a high level of nucleotide identity (>95\%) with the Y-chromosomal texim $Y$ genes as well as a very similar gene structure (Figure 2). Hence, texim1 might correspond to the molecular progenitor of texim $Y$ sequences, or texim1 is a (pseudo)autosomal duplicate of one of the texim $Y$ genes. Three more divergent texim genes were also detected in the genome, with one of them, texim2, mapping to autosomal linkage group 18. Altogether, four copies of texim are present in platyfish (pseudo)autosomal parts of the genome, with three additional Y-specific copies only in males.
Texim genes encode putative SGNH hydrolases found in fish and other metazoans

In silico analysis of conserved domains identified a SGNH hydrolase domain in the predicted Texim proteins. This domain, which is found in certain esterases and lipases with broad substrate specificity and regiospecificity [17], is characterized by four invariant catalytic residues: the catalytic serine (S) at the $\mathrm{N}$-terminus in conserved block I, a glycine (G) in conserved block II, an asparagine $(\mathrm{N})$ in conserved block III and the catalytic histidine $(\mathrm{H})$ in conserved block IV (Figure 3). An aspartate residue (D) is often present in block IV. The four major residues (S, G, N and $\mathrm{H}$ ) are important for activity, with a different catalytic mechanism when compared to common alpha/beta-hydrolases [18].

Sequence database analysis identified texim sequences in different fish species including killifish, medaka (2 very similar copies on chromosomes 10 and 21), pufferfish (one copy in Sphoeroides nephelus), sea bass, Atlantic cod (one copy) and gar (one copy). No sequence was detected in zebrafish. Texim sequences were also found in Oikopleura (urochordate, one copy), in Amphioxus (cephalochordate, three copies) and sea urchins (echinoderms, two copies). Texim genes were absent from mammals and other tetrapods, suggesting loss of these sequences after divergence from the fish lineage 400-450 million years ago, or alternatively introduction of texim into the fish lineage through horizontal gene transfer.

All identified Texim sequences form a phylogenetic group distinct from other proteins with SGNH domains (Figure 4). Within the SGNH hydrolase family, Texim proteins are related to proteins from very different origins, including bacterial hydrolases, animal plateletactivating factor acetylhydrolases (PAFah) and proteins encoded by animal CR1 retrotransposons. No reverse 


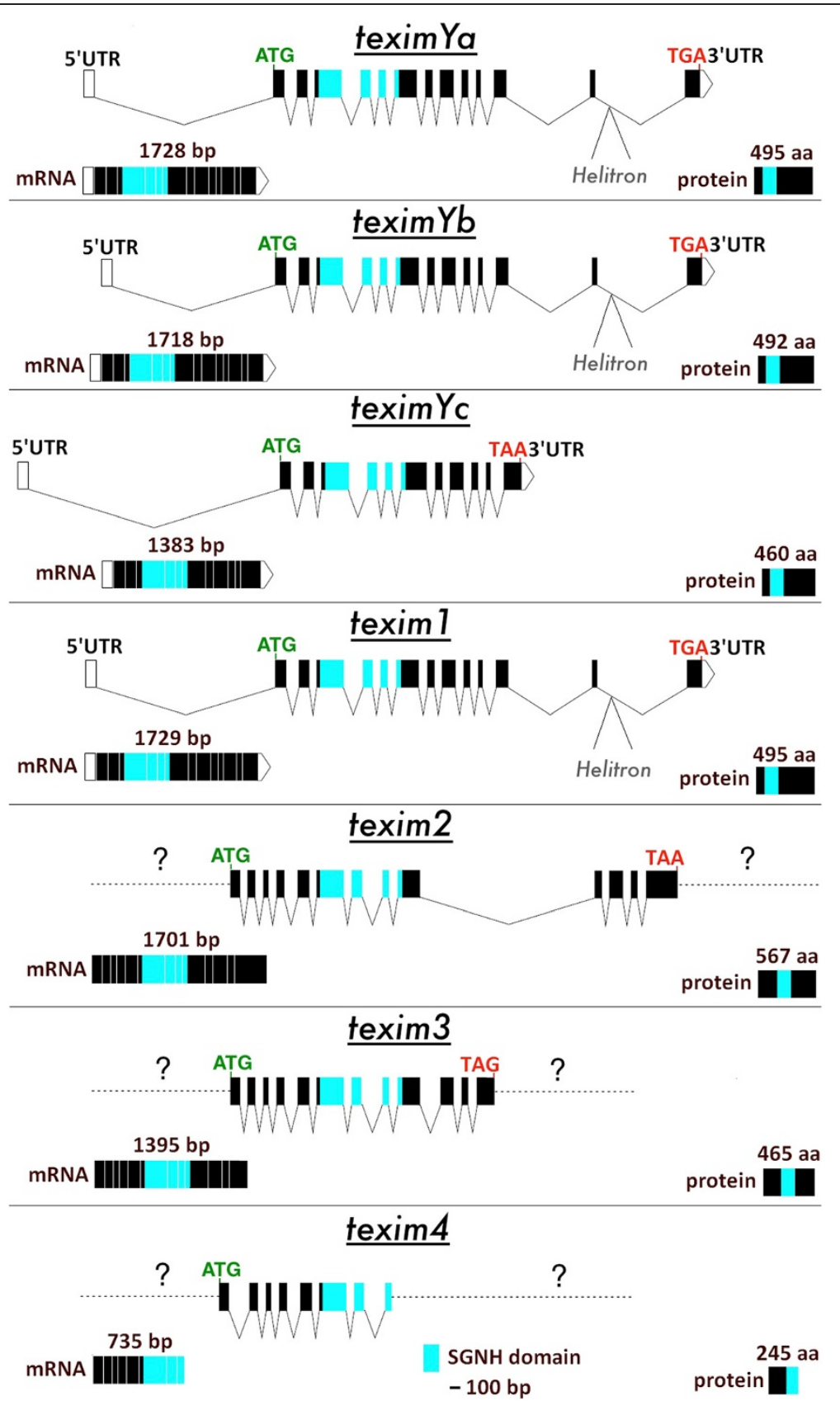

Figure 2 Exon/intron structure of texim genes in the platyfish genome. The SGNH hydrolase domain(-coding region) is marked in light blue. Introns are represented by broken lines. Predicted start codons are in green and stop codons in red. CDNA and predicted protein sizes are provided. Helitron transposon positions are indicated. Question marks indicate lack of information due to absence of sequence data. Both coding and protein sequences of texim4 are partial.

transcriptase was found to be associated with any texim sequence, suggesting that texim is not part of a CR1 retrotransposon.

Texim is associated with Helitron transposons in fish but not in other animals

For all platyfish texim genes for which enough flanking sequence data was available for analysis, a Helitron transposon coding region was identified at the close vicinity 3 ' from texim genes (3 $\mathrm{kb}$ downstream from the stop codon of texim2) or even in the last intron for teximY/1 (Figures 2 and 5). Helitrons are eukaryotic rolling-circle DNA transposons $[19,20]$. They are able to capture and mobilize gene sequences in certain organisms and might therefore play a role in gene evolution through exon shuffling and gene duplication 


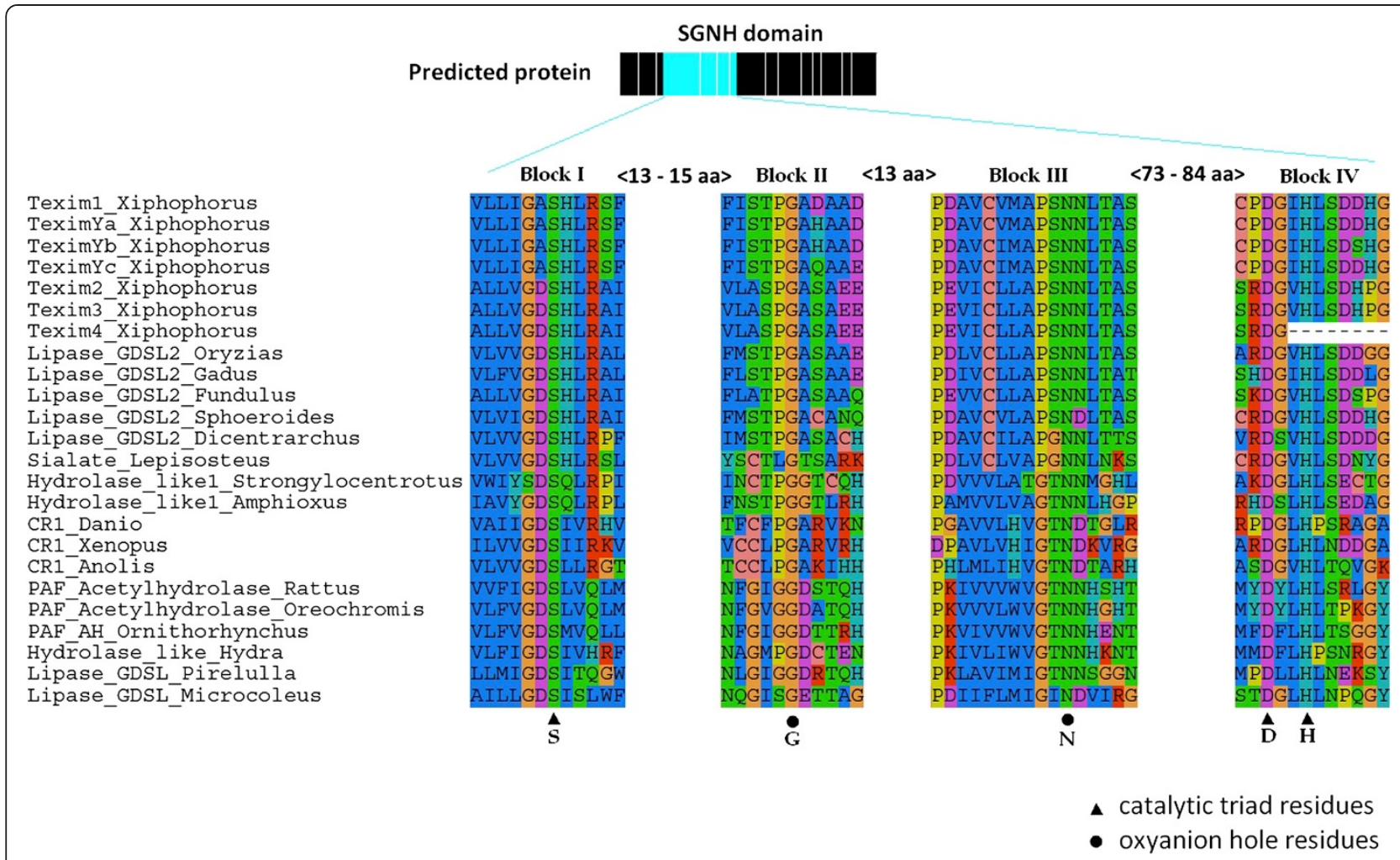

Figure 3 Conserved amino-acid blocks in the SGNH domain of predicted Texim proteins. Critical residues important for catalytic activity

and oxyanion hole residues are indicated, as well as minimum-maximum amino-acid distances between the domains.

$[21,22]$. Texim was also found to be associated with Helitrons in other fish species including medaka, pufferfish and sea bass (Figure 5). Association between texim sequences and Helitrons transposons was found neither in Oikopleura (which does not have Helitrons) nor in Amphioxus and sea urchins (which contain Helitrons). These observations suggested capture and mobilization of an ancestral texim gene by a Helitron element in the fish lineage after divergence from urochordates/cephalochordates. "Free" Helitron transposons not associated with texim genes are present in zebrafish (which is devoid of texim genes) as well as in platyfish and other fish species possessing texim-Helitron associations.

\section{TeximY genes are preferentially expressed in testis in adult platyfish}

Expression of $X$. maculatus texim genes was analyzed by RT-qPCR in the Rio Jamapa population used to construct the BAC library (XY males and XX females, Figure 6), as well as in the Rio Usumacinta population (YY males and WY females) (Figure 7). The (pseudo)autosomal copies of texim, namely texim1, texim2, texim3 and texim4, were all detected by PCR in genomic DNA of both males and females of the Rio Usumacinta population. From the three Y-linked copies, only texim $Y b$ was found in Rio
Usumacinta. In this population, texim $Y b$ was detected by PCR in both males and females, suggesting localization either on the $\mathrm{Y}$ chromosome-specific segment or on (pseudo)autosomal regions.

In both populations, teximYa (when present) and texi$m Y b$ were both preferentially expressed in testis, with texim $Y b$ being almost exclusively expressed in the male gonad (Figures 6 and 7). We could not detect any expression for texim $Y_{c}$, suggesting that this truncated sequence corresponds to a pseudogene. Texim1 was strongly expressed in testis and also in gills in both platyfish populations. In addition, a significant expression was found in ovary in the Rio Jamapa population. Expression of other texim genes was generally strong in the testis, with exception of texim 2 and texim 3 in the Rio Jamapa population, which are predominantly expressed in the brain (Figure 6).

\section{Texim is expressed in spermatozeugmata and late spermatids in platyfish testis}

Expression of texim gene in platyfish adult testis was further analyzed by in situ RNA hybridization. Histological analysis of the platyfish testis revealed the presence of many spermatozeugmata, i.e. the aggregation of mature sperm (Figure 8A). Hence, the testis analyzed was at stage VI of maturation (according to [23]). The vasa gene, 


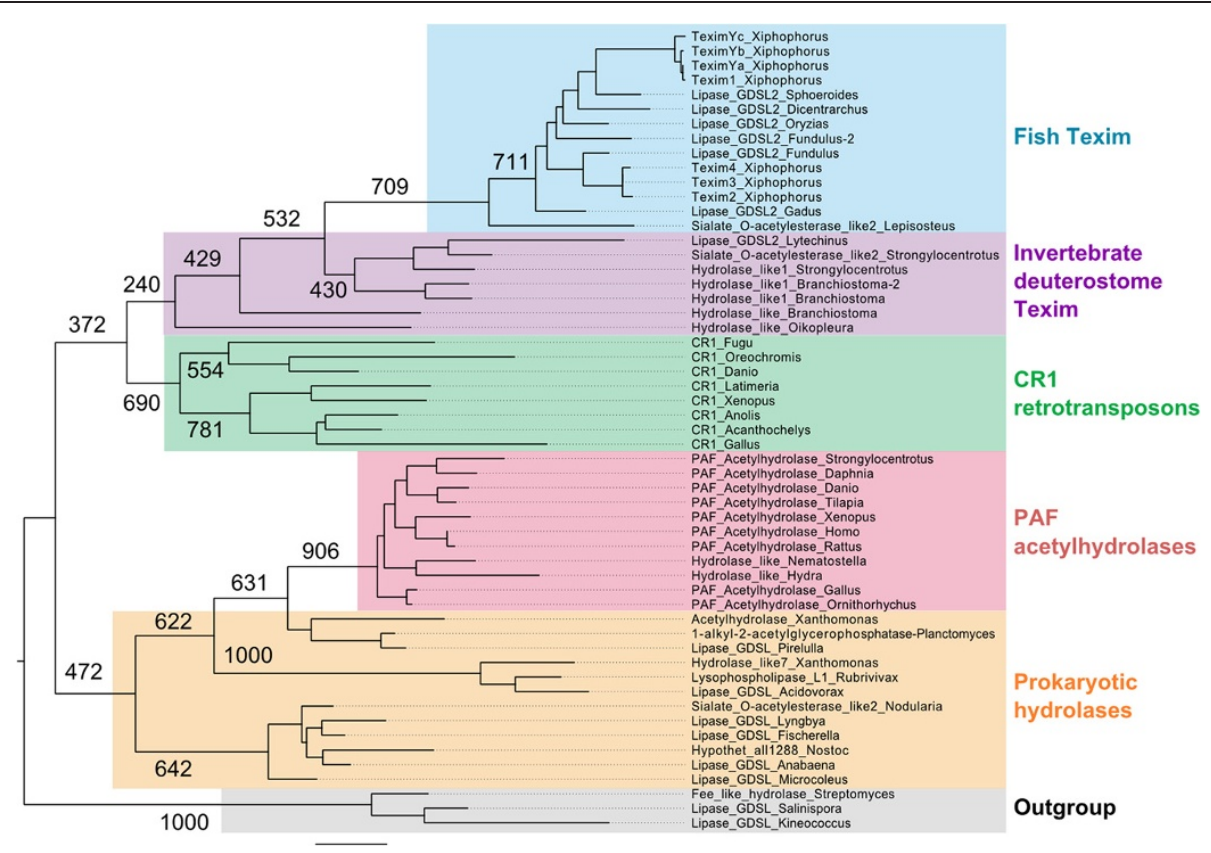

Figure 4 Maximum likelihood phylogenetic tree of Texim-related SGNH hydrolase protein domains found in different organisms. The Maximum Likelihood phylogenetic tree is based on an alignment of 112 amino-acids from the SGNH hydrolase domains. Bootstrap values are indicated (1000 repetitions). Accession numbers: Fish Texim: Lipase_GDSL2_Sphoeroides: Sphoeroides nephelus, protein prediction, AF094698.1; Lipase_GDSL2_Dicentrarchus: Dicentrarchus labrax, protein prediction, LG1, FQ310506.3; Lipase_GDSL2_Oryzias: Oryzias latipes, protein prediction, ENSEMBL, LG1:Scaffold 395; Lipase_GDSL2_Fundulus-2: Fundulus grandis, JW608837.1; Lipase_GDSL2_Fundulus: Fundulus grandis, JW617431.1; Lipase_GDSL2_Gadus: Gadus morhua, consensus sequence from ESTs EL616197.1, ES481574.1 and ES474748; Sialate_O-acetylesterase_like2_Lepisosteus: Lepisosteus oculatus, protein prediction, LG7. Invertebrate deuterostome Texim: Hydrolase_like1_Amphioxus: Branchiostoma floridae, XP_002590490.1; Hydrolase_like1_Amphioxus-2: Branchiostoma floridae, protein prediction, scaffold 113; Hydrolase_like1_Strongylocentrotus: Strongylocentrotus purpuratus, protein prediction, scaffold 80934; Lipase_GDSL2_Lytechinus: Lytechinus variegatus, J1442514.1; Sialate_O-acetylesterase_like2_ Strongylocentrotus: Strongylocentrotus purpuratus, XP_003726742.1; Hydrolase_like_Amphioxus: Branchiostoma floridae, XP_002586334.1; Hydrolase_like_Oikopleura: Oikopleura dioica, CBY22153.1. Accession numbers for PAF acetylhydrolases, prokaryotic hydrolases, CR1 retrotransposons and outgroups are available upon request.

encoding an RNA helicase of the DEAD box protein family, was used as a control for gene expression in germ line [24]. According to expression patterns observed in other fish species, vasa was expressed in spermatogonia and primary spermatocytes in the platyfish (Figure $8 \mathrm{~B} / \mathrm{C}$ ). In situ hybridization for texim1/texim $Y$ (the probe used does not allow to differentiate between texim $Y$ and texim1) showed expression in late spermatids and spermatozeugmata, i.e. at late stages of spermatogenesis (Figure $8 \mathrm{D} / \mathrm{E}$ ).

\section{Discussion}

Gene duplications play a major role in the formation of novel master sex-determining genes in fish $[5,7,9]$ and other organisms $[25,26]$. New master genes appearing at the top of the sex determination cascade are generally derived from genes already involved in sexual development, as exemplified by the $d m r t 1 b Y$ master gene of the medaka [5,6]. However, exceptions may exist, as suggested for the immune gene paralog $s d Y$ recruited as the master sex-determining gene in the rainbow trout [9]. Frequently, master sex-determining genes in vertebrates encode transcription factors ( $S r y$ in therians, $D m-W$ in
Xenopus laevis, Dmrt1 in Gallus gallus, dmrt1bY in Oryzias latipes), but some recent data have demonstrated that it is not the general rule, at least in fish $\left(g s d f^{Y}\right.$ in Oryzias luzonensis, amhY in Odontesthes hatcheri and amhr2 in Takifugu rubripes $[7,8,10])$. Importantly, all master sex-determining genes identified so far in fish are expressed in the same manner, in somatic cells surrounding the germ cells of the differentiating gonads.

In the platyfish Xiphophorus maculatus, an ovoviviparous teleost species, the master sex-determining gene has not been identified so far. Only a few functional genes have been described in the sex-determining region, including the multicopy melanocortin receptor gene $m c 4 r$, which controls the onset of puberty and is present on both the $\mathrm{X}$ and the $\mathrm{Y}$ chromosomes [14,27].

In this study, we have identified a new multicopy gene called texim $Y$, triplicated on the $\mathrm{Y}$ but absent from the $\mathrm{X}$ chromosome. Texim $Y$ genes are located at distances between 80 and $280 \mathrm{~kb}$ near $Y$-cript, a Y-specific pseudogene linked to the sex-determining locus. The sex-determining region of the platyfish is very rich in repetitive DNA [16]. Accordingly, the repeat content of the $0.5 \mathrm{Mb}$ region 


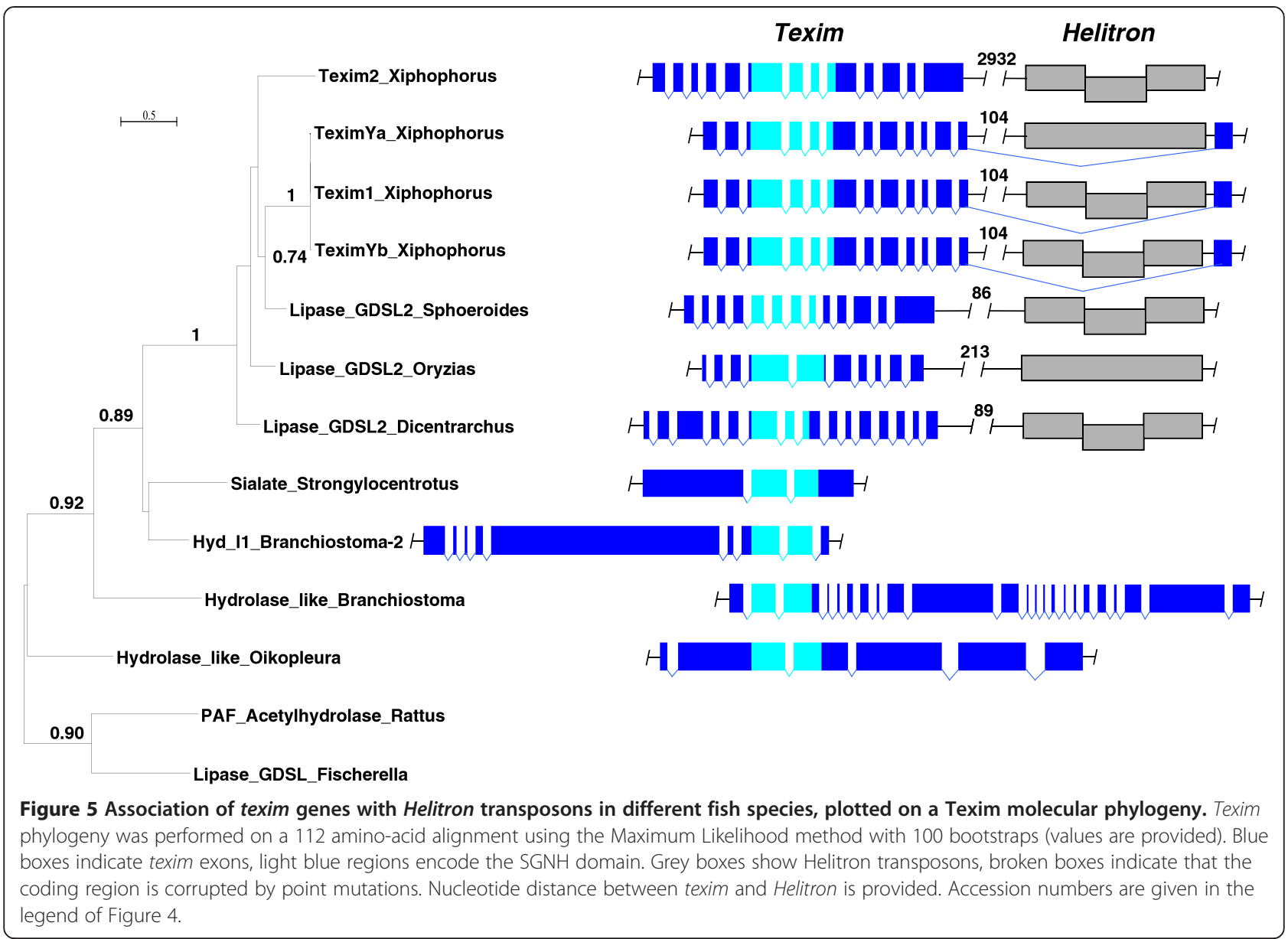

analyzed in this study is as high as $65.2 \%$ (unpublished results). In addition, the region containing the master sex-determining gene is characterized by a high level of genomic plasticity, with frequent rearrangements such as duplications, deletions and transpositions [12,16]. The presence of three copies of texim is consistent with the frequent duplications observed in this region. The autosomal texim1 gene is a possible molecular ancestor of the Y-linked cluster. Y-chromosomal texim copies might be the result of mobilization by the flanking Helitron transposons, or might have been embedded in larger segmental duplication events. Texim $Y$ genes are preferentially expressed in the testis. Hence, the situation observed on the sex chromosomes of the platyfish is consistent with the observation that new sex-biased genes, especially male-biased genes, can be formed on sex chromosomes through the duplication of autosomal genes [28].

There is so far neither biochemical nor biological data concerning the functions of TeximY. Identification of conserved SGNH hydrolase domains in predicted sequences strongly suggests that Texim proteins work as esterases/lipases [17]. In contrast to master sexdetermining genes described so far in fish, texim $Y$ genes are not expressed in somatic cells in the adult testis. Hence, texim $Y$ genes might not correspond to platyfish master sex-determining genes. However, additional expression analyses remain to be performed to test if these genes are expressed during embryonic development at the onset of sex determination.

We have shown that texim $Y$ genes are expressed in late spermatids and spermatozeugmata, suggesting that these genes might function at late stages of spermatogenesis. Interestingly, Texim is related to the platelet-activating factor (PAF) acetylhydrolase (PAFah) present in different animals. In mammals, PAFah is involved in reproduction [29-34], but also in other biological processes such as development, inflammation, hemostasis and apoptosis. This enzyme regulates PAF activity via deacetylation [29]. It reduces the level of PAF [33], but can also be involved in signaling pathways via interaction with other proteins in different tissues including testis $[32,33,35,36]$. Recently, a new testisspecific protein isoform of Pafah1b2 with possible role in spermatogenesis has been identified, the knock-out of which causes male infertility in the mouse [32].

Texim proteins are also related to prokaryotic proteins. Hence, either prokaryotic or eukaryotic texim-like 


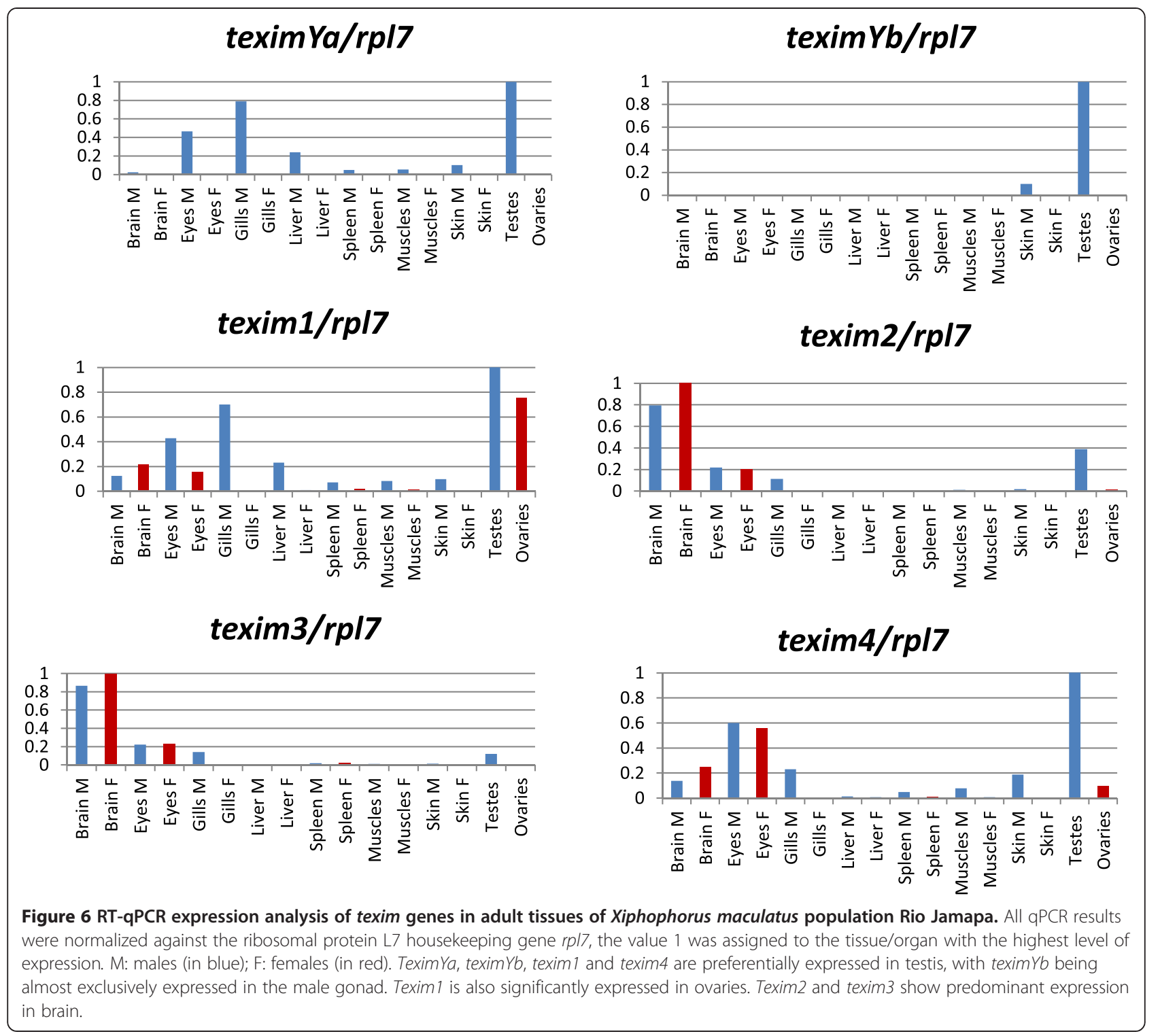

genes share a very ancient common ancestor, or a horizontal transfer between prokaryotes and eukaryotes was involved in the evolution of texim-like sequences. In addition, Texim proteins show homology to proteins with esterase domains encoded by animal CR1 retrotransposons. These enzymes might play a role in interactions with cellular membranes, helping the element in penetrating host cells and possibly facilitating horizontal transfer [37]. Texim genes are not parts of retrotransposons, since they possess multiple introns and are not associated with reverse transcriptase genes. However, we cannot exclude that texim sequences have evolved from ancestral CR1-like elements.

Interestingly, texim sequences in fish are associated with another type of transposons, rolling circle DNA transposons called Helitrons. Such elements have been already identified on the sex chromosomes of the platyfish [38]. Helitrons are able to capture and mobilize resident coding sequences particularly in plants, and might therefore be involved in the evolution of gene functions through exon shuffling and gene duplication [21,22]. The absence of association between texim and Helitrons in urochordates, cephalochordates and echinoderms suggests that the capture event took place specifically in the fish lineage. Texim genes might facilitate Helitron transposition and transmission in a way similar to the role proposed for the Texim-related esterase in CR1 retrotransposons [37]. However, most Helitron transposons are not associated with texim in teleosts, indicating that mobilization and spread of Helitrons do not absolutely require Texim even in fish. Patchy distribution of texim in fish and other vertebrates suggests either recurrent 


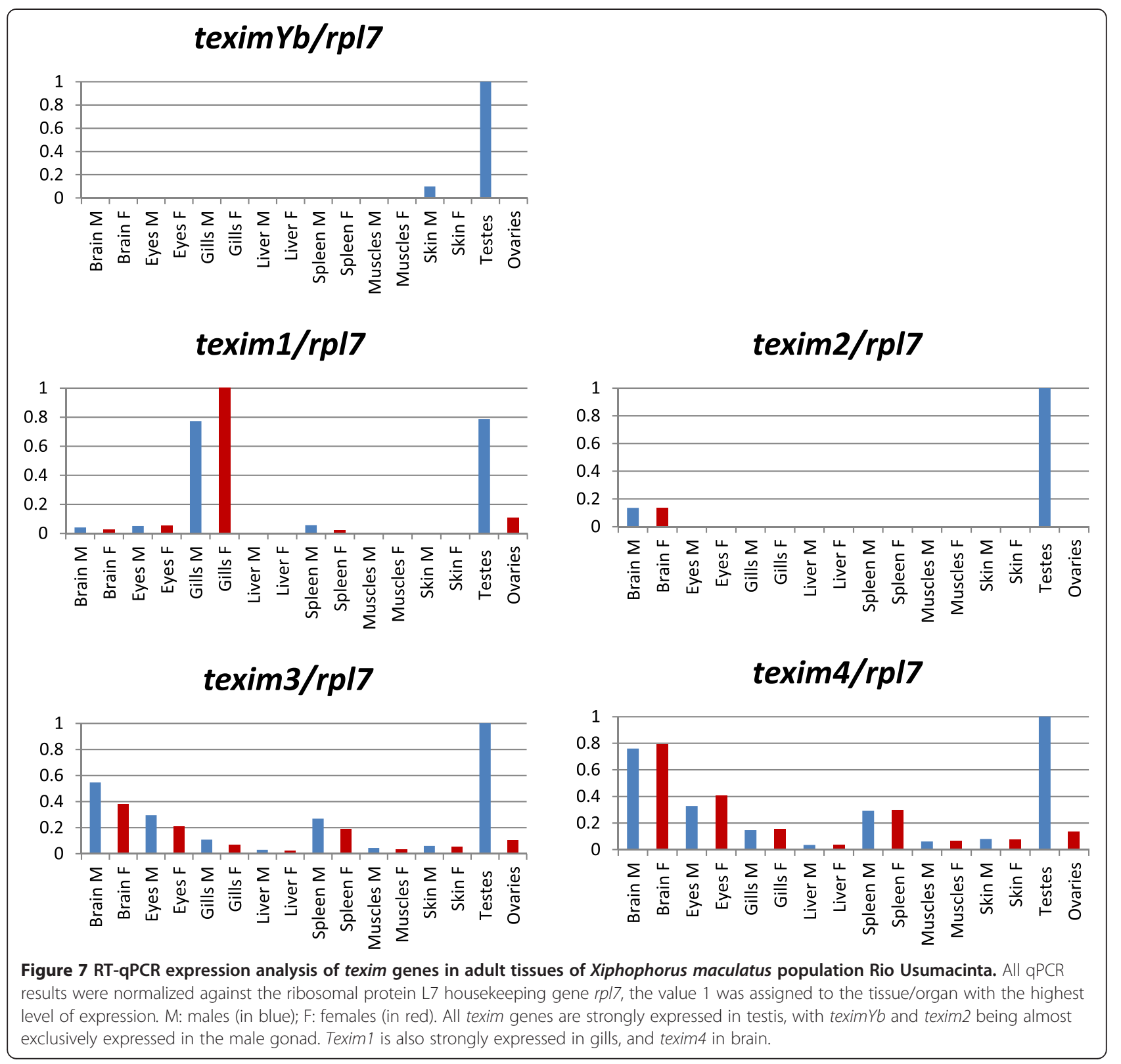

loss of texim (e.g., in zebrafish and tetrapods) or horizontal transfer of texim, possibly in association with Helitrons.

\section{Conclusions}

Texim genes in the platyfish uncover a novel multigene family encoding proteins with SGNH hydrolase domain, for which no functional data is available so far. The Yspecific copies teximYa and texim $Y b$ have no counterparts on the $\mathrm{X}$ chromosome and are specifically expressed in late spermatids and spermatozeugmata. Texim genes are associated with Helitrons in fish genomes, suggesting that they have been captured and mobilized by these transposons. Two non-exclusive hypotheses can explain these results. On the one hand, texim genes might have been maintained in Helitrons because Texim proteins facilitate the transposition or transmission of these elements. Alternately, texim genes might correspond to fertility genes with advantageous male functions mobilized and spread by Helitrons transposons. Such genes, which may have deleterious effects on females, are frequently located on the male-specific $\mathrm{Y}$ chromosome in animals. Fish present a very important evolutionary turn-over of sex chromosomes. Transposonmediated mobility of fertility genes might allow the rapid fixation of spermatogenesis genes on neo-Y chromosomes, as suggested by the presence of three texim $Y$ genes on the $\mathrm{Y}$ but not on the $\mathrm{X}$ chromosome of the platyfish. 

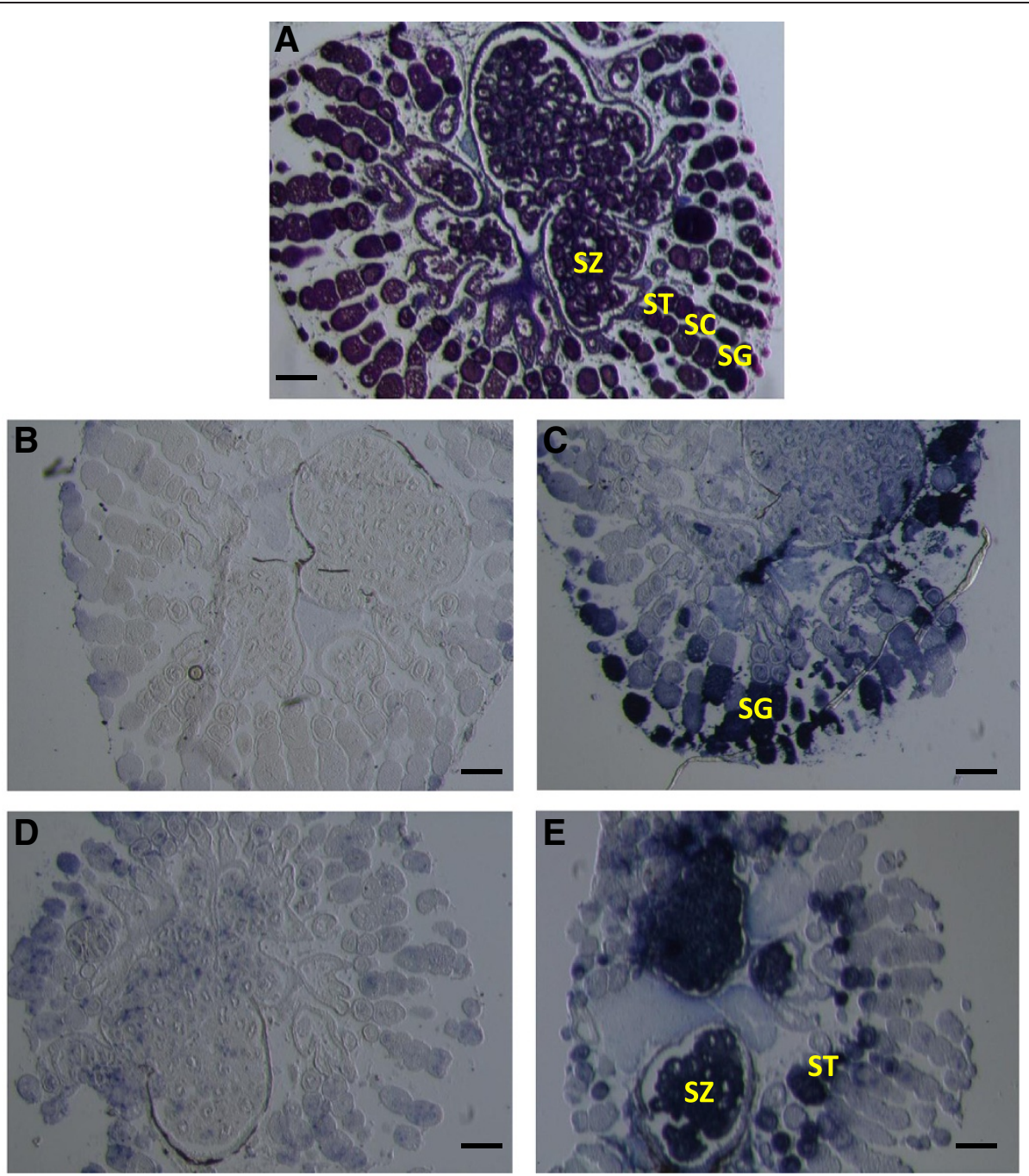

Figure 8 In situ RNA hybridization analysis of vasa and texim 1/Y expression in platyfish adult testis. A. Transversal testis section stained with Masson's trichrome. B. Vasa sense probe, C. Vasa antisense probe, D. Texim sense probe, E. Texim antisense probe. SG, spermatogonia; SC, spermatocytes; ST, spermatids; SZ, spermatozeugmata. The probe used does not allow to differentiate between teximY and texim1. Scale bars: $50 \mu \mathrm{m}$.

\section{Methods}

Fish

Xiphophorus maculatus males and females analyzed in this study belong to populations Rio Jamapa (Jp163A) and Rio Usumacinta (Up-2) reared at the Plateau de Recherche Expérimentale de Criblage In vivo (PRECI) of the SFR BioSciences Gerland - Lyon Sud (US8/UMS3444, Lyon, France) and the fish facility of the Biozentrum at the University of Würzburg (Germany). Fishes were kept under standard conditions and sacrificed following protocols in accordance with regulations from the French Ministry of Agriculture and the European Union (agreement number A693870602).

\section{In silico sequence analysis}

Gene structure and protein sequences were predicted using FGENESH with the fish training set (http://softberry.com).
Intron-exon structure was determined by sequence comparison with Expressed Sequence Tags (ESTs) downloaded from Genbank as well as by sequencing of RTPCR and RACE-PCR products. BLAST analyses were mainly performed against sequence databases accessible from the NCBI (http://www.ncbi.nlm.nih.gov/BLAST/) and ENSEMBL (www.ensembl.org) servers. Sequence alignments were done using MUSCLE [39] via SeaView [40,41] and BioEdit [42]. Phylogenetic reconstructions were performed by Maximum Likelihood using PhyML 4.0 with 1000 bootstrap repetitions under the LG model, with the following additional parameters: optimized invariable sites, BioNJ as a starting tree and Best of NNI \& SPR tree searching options [41]. The VISTA online software was used to perform alignments with mVISTA plot in order to visualize the level of sequence conservation 
(http://genome.lbl.gov/vista/mvista/submit.shtml). Conserved protein domains were detected via NCBI (http:// www.ncbi.nlm.nih.gov/Structure/cdd/wrpsb.cgi), PFAM (http://pfam.sanger.ac.uk/) [43] and annotated with Gene Ontology terms (http://www.geneontology.org/) [44]. Xiphophorus autosomal and Y-linked texim sequences have been deposited in GenBank under accession numbers [KF433067- KF433073].

\section{Gene expression analysis}

Total RNA was extracted from brain, eyes, gills, liver, spleen, muscle, skin and gonads of $X$. maculatus males and females from the Rio Jamapa and Rio Usumacinta populations using the TRIZOL reagent (Molecular Research Center, Inc.). Reverse transcription was performed with $1 \mu \mathrm{g}$ of total RNA using RevertAid First Strand Synthesis kit and oligo-dT primers (Fermentas). Expression patterns were determined by quantitative RT-PCR using gene-specific primer pairs. Primers used were GCTGCTTGCAGTTTGGATT and GTTTGATG GAGCCATGACA for teximYa, AGCCACGGGATGCA GAT and GTTCCTGTCCCTTAACCACAAC for texi$m Y b$, AGCCACGGGATGCAGAT and GTTCCTGTCC CTTAACCACAAC for texim1, CCTCTGCGGAAGAG TTGAAG and GTACGCAACAAAGCGTCAAA for texim2, GGAGACCTGCTGGACTCTTC and TTCCAC CTTCGGACAACATA for texim3, and GACGCTCTG AGGCAGCTAA and CATCACGGGAGGCAACAT for texim4. Analysis of relative gene expression was done using the DeltaDeltaCt method [45]. All qPCR results were normalized against the ribosomal protein L7 housekeeping gene rpl7 ([46,47] Additional file 1: Figure S1).

\section{In situ RNA hybridization}

In order to generate probes for in situ hybridization, platyfish vasa (663 bp, [GenBank: KF424536], primers GGTTACCGTGGAAAAGACGA and CACCTTTCCTC TCCCAATCA) and texim1 (542 bp, primers TTGGCT GTCTGTTCTCGTTG and GAGAAACGGACAGGATT GGA) partial cDNAs were amplified by PCR from testis. Amplified fragments were cloned into the $\mathrm{pCR}^{\oplus} \mathrm{II}$ vector (Invitrogen Life Technologies). Digoxigenin (DIG)-labeled antisense RNA probes were synthesized by in vitro transcription from HindIII-linearized plasmid constructs using the SP6 RNA polymerase, while negative control sense RNA probes were produced from XhoI-linearized constructs using the T7 RNA polymerase. In situ hybridizations were performed on testis sections. Testes were fixed in 4\% paraformaldehyde (PFA) in Phosphate Buffered Saline (PBS) buffer at $4^{\circ} \mathrm{C}$ overnight. After several washes in ethanol and then in toluene, testes were embedded in paraffin. Sections of $8 \mu \mathrm{m}$ were cut using a microtome and then slides were prepared. After deparaffinization of slides with xylene followed by several washes in $100 \%$ and $70 \%$ ethanol and PBS, testes were incubated for $20 \mathrm{~min}$ with proteinase $\mathrm{K}(20 \mu \mathrm{g} / \mathrm{mL})$. Prehybridization was performed for 1 hour at room temperature in the hybridization buffer composed of $50 \%$ formamide, 20X Saline Sodium Citrate (SSC) buffer, 0.1\% Tween-20, $10.5 \mu \mathrm{g} / \mathrm{ml}$ yeast tRNA, $0.05 \mathrm{mg} / \mathrm{ml}$ heparin, $5 \mu \mathrm{g} / \mathrm{ml} \mathrm{sal-}$ mon sperm DNA and 1X Denhardt's solution in diethylpyrocarbonate (DEPC)-treated water. Both antisense and sense probes were diluted in the hybridization buffer for 3 min at $80^{\circ} \mathrm{C}$. Slides with $100 \mu \mathrm{l}$ of probe $(1 \mu \mathrm{g} / \mathrm{ml})$ were covered with hybridslips and hybridized in hybridization buffer at $70^{\circ} \mathrm{C}$ overnight. The next day, after removal of hybridslips in 5X SSC, slides were washed five times in hybridization washing solution (5X SSC, 50\% formamide, $0.1 \%$ Tween-20 in distilled water) at $70^{\circ} \mathrm{C}$ for $30 \mathrm{~min}$, then two times in $2 \mathrm{X} \mathrm{SSC}$ at $70^{\circ} \mathrm{C}$ for $30 \mathrm{~min}$ and four times in Tris-Buffered Saline (TBS) buffer for $5 \mathrm{~min}$. Slides were subsequently incubated for 1 hour in a blocking solution (1 $\mathrm{mg} / \mathrm{ml}$, Roche), followed by incubation in an anti-DIG alkaline phosphatase conjugate (Roche). The next day, slides were washed four times in TBS for $5 \mathrm{~min}$ and two times in alkaline phosphatase buffer (NTMT; 0.1M Tris- $\mathrm{HCl}, 0.1 \mathrm{M}$ $\mathrm{NaCl}, 1 \mathrm{M} \mathrm{MgCl}_{2}, 0.1 \%$ Tween-20 in distilled water). Counterstaining was performed with a BM-purple solution (Roche) at room temperature until signal detection. Finally, slides were washed in PBS and mounted in Aquatex mounting media (Merck Milipore, Germany). Microphotographs were taken with Leica light microscope with 20X magnification.

\section{Additional file}

Additional file 1: Figure S1. Basal expression profile of the rpl7 gene in two populations of Xiphophorus maculatus Rio Jamapa and Rio Usumacinta. Two independent sets of cDNA have been generated from adult male and female organs: brain, eyes, gills, liver, spleen muscles, skin and gonads. Technical triplicates of each cDNA have been performed on the same qRT-PCR plate. Experiments were done with the Bio-Rad kit using the following PCR program: 40 cycles of $94^{\circ} \mathrm{C}$ and $59^{\circ} \mathrm{C}$. Ct (Threshold cycle) values were averaged and standard deviation has been calculated.

\section{Competing interests}

The authors declare that they have no competing interests.

\section{Authors' contributions}

MT performed molecular genetic experiments and bioinformatic sequence analyses, and drafted the manuscript. DC participated in bioinformatic sequence analyses. MS was involved in study design, interpretation of results and manuscript editing. DG contributed to the analysis of experimental results. JNV designed and coordinated the study, participated in data analysis and edited the manuscript. All authors read and approved the manuscript.

\section{Acknowledgements}

This work was supported by a PhD fellowship from the French Ministry of Education and Research to MT and grants from the Agence Nationale de la Recherche (ANR) to JNV.

\section{Author details}

${ }^{1}$ Institut de Génomique Fonctionnelle de Lyon, Ecole Normale Supérieure de Lyon, Centre National de la Recherche Scientifique UMR 5242, Université de 
Lyon I, 46 allée d'Italie, Lyon 69364, Lyon Cedex 07, France. ²Physiologische Chemie, Biozentrum, University of Würzburg, Am Hubland, and Comprehensive Cancer Center, University Clinic Würzburg, Josef Schneider Straße 6, Würzburg 97074, Germany. ${ }^{3}$ Present address: Center for Medical Genomics, Department of Biology, Penn State University, University Park, PA 16802, USA.

Received: 18 July 2013 Accepted: 19 March 2014

Published: 8 April 2014

\section{References}

1. Devlin RH, Nagahama Y: Sex determination and sex differentiation in fish: an overview of genetic, physiological, and environmental influences. Aquaculture 2002, 208:191-364.

2. Kikuchi K, Hamaguchi S: Novel sex-determining genes in fish and sex chromosome evolution. Dev Dyn 2013, 242:339-353.

3. Kobayashi $Y$, Nagahama Y, Nakamura M: Diversity and plasticity of sex determination and differentiation in fishes. Sex Dev 2012, 7:115-125.

4. Volff JN, Nanda I, Schmid M, Schartl M: Governing sex determination in fish: regulatory putsches and ephemeral dictators. Sex Dev 2007, 1:85-99.

5. Matsuda M, Nagahama Y, Shinomiya A, Sato T, Matsuda C, Kobayashi T, Morrey CE, Shibata N, Asakawa S, Shimizu N, Hori H, Hamaguchi S, Sakaizumi M: $D M Y$ is a Y-specific DM-domain gene required for male development in the medaka fish. Nature 2002, 417:559-563.

6. Nanda I, Kondo M, Hornung U, Asakawa S, Winkler C, Shimizu A, Shan Z, Haaf T, Shimizu N, Shima A, Schmid M, Schartl M: A duplicated copy of DMRT1 in the sex-determining region of the $Y$ chromosome of the medaka, Oryzias latipes. Proc Natl Acad Sci U S A 2002, 99:11778-11783.

7. Myosho T, Otake H, Masuyama H, Matsuda M, Kuroki Y, Fujiyama A, Naruse K, Hamaguchi S, Sakaizumi M: Tracing the emergence of a novel sex-determining gene in medaka, Oryzias luzonensis. Genetics 2012, 191:163-170.

8. Hattori RS, Murai Y, Oura M, Masuda S, Majhi SK, Sakamoto T, Fernandino Jl, Somoza GM, Yokota M, Strüssmann CA: A Y-linked anti-Mullerian hormone duplication takes over a critical role in sex determination. Proc Natl Acad Sci U S A 2012, 109:2955-2959.

9. Yano A, Guyomard R, Nicol B, Jouanno E, Quillet E, Klopp C, Cabau C, Bouchez O, Fostier A, Guiguen Y: An immune-related gene evolved into the master sex-determining gene in rainbow trout, Oncorhynchus mykiss. Curr Biol 2012, 22:1423-1428.

10. Kamiya T, Kai W, Tasumi S, Oka A, Matsunaga T, Mizuno N, Fujita M, Suetake H, Suzuki S, Hosoya S, Tohari S, Brenner S, Miyadai T, Venkatesh B, Suzuki Y, Kikuchi K: A trans-species missense SNP in Amhr2 is associated with sex determination in the tiger pufferfish, Takifugu rubripes (fugu). PLoS Genet 2012, 8:e1002798.

11. Graham P, Penn JK, Schedl P: Masters change, slaves remain. Bioessays 2003, 25:1-4.

12. Schultheis C, Böhne A, Schartl M, Volff JN, Galiana-Arnoux D: Sex determination diversity and sex chromosome evolution in poeciliid fish. Sex Dev 2009, 3:68-77.

13. Froschauer A, Körting C, Katagiri T, Aoki T, Asakawa S, Shimizu N, Schartl M, Volff JN: Construction and initial analysis of bacterial artificial chromosome (BAC) contigs from the sex-determining region of the platyfish Xiphophorus maculatus. Gene 2002, 295:247-254.

14. Volff JN, Selz Y, Hoffmann C, Froschauer A, Schultheis C, Schmidt C, Zhou Q, Bernhardt W, Hanel R, Böhne A, Brunet F, Ségurens B, Couloux A, BernardSamain S, Barbe V, Ozouf-Costaz C, Galiana D, Lohse MJ, Schartl M: Gene amplification and functional diversification of melanocortin 4 receptor at an extremely polymorphic locus controlling sexual maturation in the platyfish. Genetics 2013, 195:1337-1352.

15. Schartl M, Walter RB, Shen Y, Garcia T, Catchen J, Amores A, Braasch I, Chalopin D, Volff JN, Lesch KP, Bisazza A, Minx P, Hillier L, Wilson RK, Fuerstenberg S, Boore J, Searle S, Postlethwait JH, Warren WC: The genome of the platyfish, Xiphophorus maculatus, provides insights into evolutionary adaptation and several complex traits. Nat Genet 2013, 45:567-572.

16. Volff JN, Körting C, Froschauer A, Zhou Q, Wilde B, Schultheis C, Selz Y, Sweeney K, Duschl J, Wichert K, Altschmied J, Schartl M: The Xmrk oncogene can escape nonfunctionalization in a highly unstable subtelomeric region of the genome of the fish Xiphophorus. Genomics 2003, 82:470-479.
17. Akoh CC, Lee GC, Liaw YC, Huang TH, Shaw JF: GDSL family of serine esterases/lipases. Prog Lipid Res 2004, 43:534-552.

18. Lo YC, Lin SC, Shaw JF, Liaw YC: Crystal structure of the Escherichia coli thioesterase I/protease I/lysophospholipase L1: consensus sequence blocks constitute the catalytic center of SGNH-hydrolases through a conserved hydrogen bond network. J Mol Biol 2003, 330:539-551.

19. Kapitonov W, Jurka J: Rolling-circle transposons in eukaryotes. Proc Natl Acad Sci U S A 2001, 98:8714-8719.

20. Thomas J, Schaack S, Pritham EJ: Pervasive horizontal transfer of rolling-circle transposons among animals. Genome Biol Evol 2010, 2:656-664.

21. Du C, Caronna J, He L, Dooner HK: Computational prediction and molecular confirmation of Helitron transposons in the maize genome. BMC Genomics 2008, 9:51.

22. Hollister JD, Gaut BS: Population and evolutionary dynamics of Helitron transposable elements in Arabidopsis thaliana. Mol Biol Evol 2007, 24:2515-2524

23. Van den Hurk R, Peute J, Vermeij JAJ: Ultrastructural study of the testis of the black molly (Mollienisia latipinna) I. The intratesticular efferent duct system. Proc Kon Ned Akad Wet Ser 1974, 77:460-469.

24. Molyneaux K, Wylie C: Primordial germ cell migration. Int J Dev Biol 2004, 48:537-544.

25. Hasselmann M, Gempe T, Schiøtt M, Nunes-Silva CG, Otte M, Beye M: Evidence for the evolutionary nascence of a novel sex determination pathway in honeybees. Nature 2008, 454:519-522.

26. Yoshimoto S, Okada E, Umemoto H, Tamura K, Uno Y, Nishida-Umehara C, Matsuda Y, Takamatsu N, Shiba T, Ito M: A W-linked DM-domain gene, $D M-W$, participates in primary ovary development in Xenopus laevis. Proc Natl Acad Sci U S A 2008, 105:2469-2474.

27. Lampert KP, Schmidt C, Fischer P, Volff JN, Hoffmann C, Muck J, Lohse MJ, Ryan MJ, Schartl M: Determination of onset of sexual maturation and mating behavior by melanocortin receptor 4 polymorphisms. Curr Biol 2010, 20:1729-1734

28. Ellegren $\mathrm{H}$, Parsch J: The evolution of sex-biased genes and sex-biased gene expression. Nat Rev Genet 2007, 8:689-698

29. Arai H, Koizumi H, Aoki J, Inoue K: Platelet-activating factor acetylhydrolase (PAF-AH). J Biochem 2002, 131:635-640.

30. Hough SR, Parks JE: Platelet-activating factor acetylhydrolase activity in seminal plasma from the bull, stallion, rabbit, and rooster. Biol Reprod 1994, 50:912-916.

31. Levine AS, Kort HI, Toledo AA, Roudebush WE: A review of the effect of platelet-activating factor on male reproduction and sperm function. J Androl 2002, 23:471-476.

32. Scott BT, Olson N, Long GL, Bovill EG: Novel isoforms of intracellular platelet activating factor acetylhydrolase (PAFAH1b2) in human testis; encoded by alternatively spliced mRNAs. Prostaglandins Other Lipid Mediat 2008, 85:69-80.

33. Yan W, Assadi AH, Wynshaw-Boris A, Eichele G, Matzuk MM, Clark GD: Previously uncharacterized roles of platelet-activating factor acetylhydrolase $1 \mathrm{~b}$ complex in mouse spermatogenesis. Proc Natl Acad Sci U S A 2003, 100:7189-7194

34. Zhu J, Massey JB, Mitchell-Leef D, Elsner CW, Kort HI, Roudebush WE: Platelet-activating factor acetylhydrolase activity affects sperm motility and serves as a decapacitation factor. Fertil Steril 2006, 85:391-394.

35. Bonin F, Ryan SD, Migahed L, Mo F, Lallier J, Franks DJ, Arai H, Bennett SA: Anti-apoptotic actions of the platelet-activating factor acetylhydrolase I alpha2 catalytic subunit. J Biol Chem 2004, 279:52425-52436.

36. Tokuoka SM, Ishii S, Kawamura N, Satoh M, Shimada A, Sasaki S, Hirotsune S, Wynshaw-Boris A, Shimizu T: Involvement of platelet-activating factor and LIS1 in neuronal migration. Eur J Neurosci 2003, 18:563-570.

37. Kapitonov W, Jurka J: The esterase and PHD domains in CR1-like non-LTR retrotransposons. Mol Biol Evol 2003, 20:38-46.

38. Zhou Q, Froschauer A, Schultheis C, Schmidt C, Bienert GP, Wenning M, Dettai A, Volff JN: Helitron transposons on the sex chromosomes of the platyfish Xiphophorus maculatus and their evolution in animal genomes. Zebrafish 2006, 3:39-52

39. Edgar RC: MUSCLE: multiple sequence alignment with high accuracy and high throughput. Nucleic Acids Res 2004, 32:1792-1797.

40. Galtier N, Gouy M, Gautier C. SEAVIEW and PHYLO WIN: two graphic tools for sequence alignment and molecular phylogeny. Comput Appl Biosci 1996, 12:543-548

41. Gouy M, Guindon S, Gascuel O: SeaView version 4: A multiplatform graphical user interface for sequence alignment and phylogenetic tree building. Mol Biol Evol 2010, 27:221-224. 
42. Hall TA: BioEdit: a user-friendly biological sequence alignment editor and analysis program for Windows 95/98/NT. Nucleic Acids Symp Ser 1999, 41:95-98.

43. Finn RD, Mistry J, Tate J, Coggill P, Heger A, Pollington JE, Gavin OL, Gunasekaran P, Ceric G, Forslund K, Holm L, Sonnhammer EL, Eddy SR, Bateman A: The Pfam protein families database. Nucleic Acids Res 2010 38:D211-D222.

44. Ashburner M, Ball CA, Blake JA, Botstein D, Butler H, Cherry JM, Davis AP, Dolinski K, Dwight SS, Eppig JT, Harris MA, Hill DP, Issel-Tarver L, Kasarskis A, Lewis S, Matese JC, Richardson JE, Ringwald M, Rubin GM, Sherlock G: Gene ontology: tool for the unification of biology. The Gene Ontology Consortium. Nat Genet 2000, 25:25-29.

45. Livak KJ, Schmittgen TD: Analysis of relative gene expression data using real-time quantitative PCR and the 2(-Delta Delta C(T)) Method. Methods 2001, 25:402-448.

46. Øvergård $A C$, Nerland $A H$, Patel S: Evaluation of potential reference genes for real time RT-PCR studies in Atlantic halibut (Hippoglossus Hippoglossus L.) during development, in tissues of healthy and NNVinjected fish, and in anterior kidney leucocytes. BMC Mol Biol 2010, 11:11-36.

47. Zhang $\mathrm{Z}, \mathrm{Hu}$ J: Development and validation of endogenous reference genes for expression profiling of medaka (Oryzias latipes) exposed to endocrine disrupting chemicals by quantitative Real-Time RT-PCR. Toxicol Sci 2007, 95:356-368.

doi:10.1186/1471-2156-15-44

Cite this article as: Tomaszkiewicz et al: A multicopy Y-chromosomal SGNH hydrolase gene expressed in the testis of the platyfish has been captured and mobilized by a Helitron transposon. BMC Genetics 2014 15:44.

\section{Submit your next manuscript to BioMed Central and take full advantage of:}

- Convenient online submission

- Thorough peer review

- No space constraints or color figure charges

- Immediate publication on acceptance

- Inclusion in PubMed, CAS, Scopus and Google Scholar

- Research which is freely available for redistribution 